\title{
The Effects of Orography on the Extratropical Transition of Tropical Cyclones: A Case Study of Typhoon Sinlaku (2008)
}

\author{
HILKE S. LENTINK \\ Institute of Meteorology and Climate Research, Karlsruhe Institute of Technology, Karlsruhe, Germany \\ CHRISTIAN M. GRAMS \\ Institute of Meteorology and Climate Research, Karlsruhe Institute of Technology, Karlsruhe, Germany, \\ and Institute for Atmospheric and Climate Science, ETH Zurich, Zurich, Switzerland \\ MICHAEL RIEMER \\ Institute for Atmospheric Physics, Johannes Gutenberg-University, Mainz, Germany \\ SARAH C. JONES \\ Deutscher Wetterdienst, Offenbach, Germany
}

(Manuscript received 27 April 2018, in final form 6 September 2018)

\begin{abstract}
Extratropical transition (ET) can cause high-impact weather in midlatitude regions and therefore constitutes an ongoing threat at the end of a tropical cyclone's (TC) life cycle. Most of the ET events occur over the ocean, but some TCs recurve and undergo ET along coastal regions; however, the latter category is less investigated. Typhoon Sinlaku (2008), for example, underwent ET along the southern coast of Japan. It was one of the typhoons that occurred during the T-PARC field campaign, providing unprecedented high-resolution observational data. Sinlaku is therefore an excellent case to investigate the impact of a coastal region, and in particular orography, on the evolution of ET. Here, observations from T-PARC are employed to verify high-resolution simulations of Sinlaku. In addition, a sensitivity simulation is performed with the orography of Japan removed. The presence of orography causes blocking of low-level, cool midlatitude air north of Japan. Without this inflow of cool air, ET is delayed. Only once Sinlaku moves away from the orographic barrier does the cool, dry environmental air penetrate equatorward, and ET continues. On a local scale, evaporatively cooled air from below Sinlaku's asymmetric precipitation field could be advected toward the cyclone center when orography was favorable for it. Changes in the vortex structure, as known from mature TCs interacting with orography, were only minor due to the high translation speed during ET. This study corroborates that orography can impact ET by modulating both the synoptic-scale environmental conditions and the mesoscale cyclone structure during ET.
\end{abstract}

\section{Introduction}

The extratropical transition (ET) of tropical cyclones (TCs) is associated with high-impact weather, both locally and in downstream regions (Jones et al. 2003; Evans et al. 2017). The local direct impact is mainly caused by strong wind gusts and excessive precipitation. These are not always well forecasted because a numerical weather prediction model is prone to small errors

Corresponding author: Hilke S. Lentink, hilke.lentink@kit.edu that evolve during the complex interaction between a poleward-moving TC and its environment. The combination of high-impact weather and low predictability forms a risk for society and threatens life and property. Despite ongoing research, the processes that occur during ET are not fully understood yet. So, in order to improve ET forecasting, there is a need to improve the dynamical understanding of ET, not only on the synoptic scale, but also the smaller-scale structural changes.

During a classic ET, the cyclone moves poleward over the ocean. Although the transition of the cyclone structure 
is a gradual development, the transformation stage (Klein et al. 2000; Ritchie and Elsberry 2001) can be divided into three phases with the following key elements. The TC first encounters a decrease of intensity due to lower sea surface temperatures (step 1); second, the vortex tilts by the influence of vertical wind shear by the midlatitude jet stream (step 2); and third, the interaction of the TC circulation with cold dry midlatitude air north of the baroclinic zone induces a frontal structure (step 3). So, when ET takes place over the ocean, the structure of the storm is changing from an almost axisymmetric warm-core cyclone into a frontal cold-core cyclone with extratropical characteristics such as a broadening low-level wind field.

Although ET is most common over the ocean (Evans et al. 2017), the transition can take place near land and orography, like Japan, New Zealand, or the U.S. East Coast. When recurving TCs are close to a coastal mountainous area, enhanced precipitation is often found due to orographic lifting (Hart and Evans 2001; Sinclair 1993). Orography does not always play a key role in heavy precipitation development, however, since the large-scale atmospheric circulation and frontogenesis are of importance as well (Colle 2003; Ritchie and Elsberry 2001). In midlatitude areas, mountain barriers can have an influence on the distribution and blocking of colder and warmer air masses. For example, cold air damming (e.g., Lackmann 2011, chapter 8) east of the Appalachians can enhance precipitation during ET (Jones et al. 2003; DiMego and Bosart 1982a,b; Bosart and Dean 1991; Srock and Bosart 2009; Atallah and Bosart 2003). Nevertheless, documented case studies of ET near land mainly mention enhanced precipitation on the large scale due to forced ascent along an orographic barrier. Not much is known about the effect of orography on the kinematic and thermodynamic changes in structure of the transitioning cyclone, both on the large and mesoscales, and the forecast errors associated with these changes.

For mature TCs that make landfall, on the other hand, many (idealized) studies document the influence of either a flat coastal region or an orographic barrier (e.g., Taiwan) on the track and structural development. When a TC vortex impinges on land, regardless of orography, it has two effects: a reduction of moisture supply and an increase of surface roughness. First, when the inner core is still over the ocean, dry air from land is transported offshore by the vortex outer circulation ( $>100 \mathrm{~km}$ from the center) and advected upward (Chan and Liang 2003). When dry air moves over moist air, this reduces the moist static stability on the offshore side, and an asymmetric convection and cloud pattern is expected (Chan and Liang 2003). Subsequently, when a TC moves closer to the shore and is situated partly over land and partly over the ocean, the difference in surface roughness has a dominant effect on vertical motion asymmetries, compared to moisture supply (Wong and Chan 2006). Differential friction induces asymmetries in the cyclone structure, with enhanced convection, diabatic production of potential vorticity (PV), and rainfall at the landward side, and additionally causes the TC to move toward land in the absence of an environmental flow (e.g., Wong and Chan 2006; Szeto and Chan 2010; $\mathrm{Li}$ et al. 2014). In the presence of environmental vertical wind shear, differences in surface roughness are of less importance to the inner-core structure ( $\mathrm{Li}$ et al. 2015).

Orography constitutes a barrier that blocks the lowerlevel airflow. Air parcels of a TC or a large-scale air mass need to flow either over the barrier or around it. As a consequence, the orography influences both the track (e.g., Chang 1982) and structural changes of a TC. The interaction of a cyclone with orography depends on many factors, such as the type and height of a barrier; the structure, size, and intensity of the TC; and the velocity and stability of the atmospheric flow (e.g., Yeh and Elsberry 1993; Lin et al. 2005; Jian and Wu 2008; Wu et al. 2015). Rapid-moving storms experience, in general, less track deflection because the time during which the mountains exert an impact on the cyclone is reduced (Yeh and Elsberry 1993). When a TC approaches an orographic barrier, several mechanisms can cause a change in vortex structure, other than the aforementioned orographic lifting. For example, the TC's wind field parallel to the barrier, between the orography and the core, is channeled and forced to accelerate. Consequently, the strongest winds are found at the landward side. Farther away from the center, the part of the circulation that has a certain angle in flow direction with respect to the orientation of the barrier is able to flow over the mountains and arrives at the offshore side after cyclonically passing the orography. A positive relative vorticity anomaly is then induced by stretching of the air column, which causes a cyclonic deflection of the outer flow toward the core. The mountain-parallel channeled flow and the deflected flow enhance convergence at the offshore side, leading to an asymmetric vertical motion pattern near the TC core (Tang and Chan 2014).

For ET, when a strong environmental background flow is present and the TC circulation is broadening, the effect of an orographic barrier, dry air inflow from land, and differential friction on the vortex structure and track deflection has, to the authors' knowledge, not yet been investigated. In this study, the objective is to gain a better understanding of the influence of orography on the structural changes during ET, from both an environmental-scale and a vortex-scale perspective. Typhoon Sinlaku (2008) was found to be a very suitable 
case study for this purpose. Sinlaku had a track close to the orography of Japan and experienced an interrupted ET when the TC unexpectedly reintensified as a tropical cyclone. We aim to understand the physical processes that governed Sinlaku's interrupted ET transformation stage and its unexpected tropical reintensification. The key question is this: What is the influence of orography on the synoptic-scale environmental conditions during the ET of Sinlaku, and how does orography influence the mesoscale cyclone structure of Sinlaku?

This paper is structured as follows. In section 2, the model and the diagnostic tools are explained. In section 3, Sinlaku's life cycle is described, as well as the model simulations. We then discuss the influence of orography on the evolution of Sinlaku's ET, first in terms of the environment (section 4), and then focusing on changes in the vicinity of the TC vortex (section 5). We then summarize and discuss our results in section 6 .

\section{Methods}

For this study, we use the nonhydrostatic, limited-area numerical weather prediction model Consortium for Small-Scale Modeling (COSMO) version 4.21, based on the primitive thermodynamic-hydrodynamic equations [see Steppeler et al. (2003) and http://www.cosmo-model. org for more details on the computational methods]. The model is set up with a horizontal resolution of $0.025^{\circ}$ (about $2.5 \mathrm{~km}$ at $35^{\circ} \mathrm{N}$ ) and 57 vertical levels up to $30-\mathrm{km}$ height, with an enhanced vertical resolution in the planetary boundary layer. Shallow convection is parameterized using the mass-flux scheme of Tiedtke (1989), while middle and high convection are explicitly computed. For all parameterized processes, the default setup of COSMO is used (Doms et al. 2011). The model is initialized with ECMWF research analysis data assimilating T-PARC dropsondes (hereafter, analysis data), available every $6 \mathrm{~h}$ on a grid with $0.25^{\circ}$ horizontal resolution.

The gridded orography of Japan, as used in the control simulation (CNTRL), is characterized by medium-high mountains (500-1500 m MSL) on the islands Kyushu and Shikoku and the western part of Honshu, and by high mountains ( $>2000 \mathrm{~m}$ MSL) in the middle of Honshu (Fig. 1). A numerical experiment is performed to investigate the impact of orography on Sinlaku's ET. In the sensitivity simulation, the orography of the islands Honshu, Shikoku, and Kyushu is flattened (JFLAT). The surface is thereby set to $0 \mathrm{~m}$ MSL, and the initial data were extrapolated to the terrain-following vertical layers of COSMO with the preprocessing program INT2LM version 1.18. For the extrapolation, the same technique is used as in Ehmele et al. (2015), Barthlott et al. (2016), and Schneider et al. (2018). The vertical

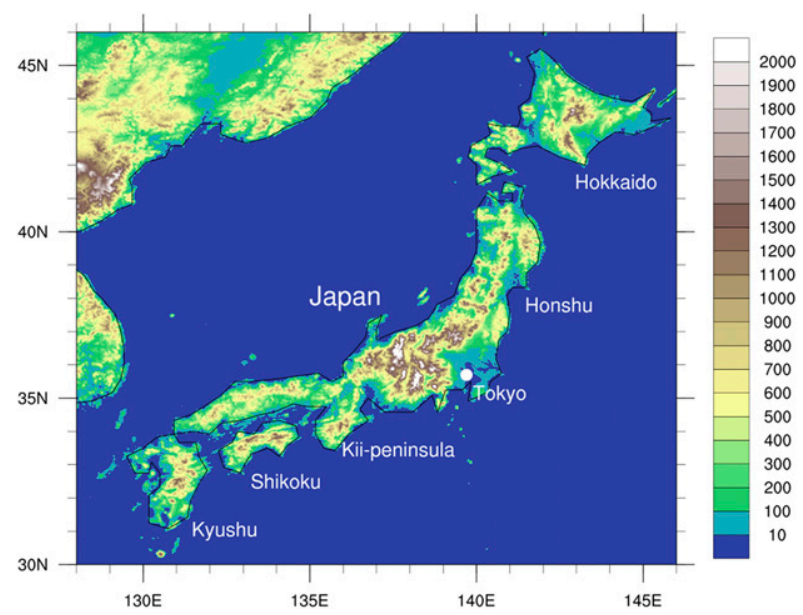

FIG. 1. Geometric height $(\mathrm{m})$ on $0.025^{\circ}$ resolution as surface boundary condition in the COSMO Model in the control simulation (CNTRL), including geographically relevant locations.

profile is split into a boundary layer and a free atmosphere, below and above the level of roughly $850 \mathrm{hPa}$. The boundary layer is shifted downward to the new surface. Subsequently, the temperature and horizontal wind are extrapolated to fill the gap between the new boundary layer and the original free atmosphere, based on their gradient at $850 \mathrm{hPa}$. For pressure perturbations, relative humidity, and vertical velocity, the gap is filled with constant values. No distinct spinup effects are found after $1-2 \mathrm{~h}$ of forecast lead time.

The development of Sinlaku during ET is analyzed both from a Lagrangian and an Eulerian perspective. For the Lagrangian perspective, trajectories of coherent air masses are calculated with the Lagrangian Analysis Tool (LAGRANTO; Wernli and Davies 1997) version 2.0 (Sprenger and Wernli 2015), and atmospheric variables can be traced along the pathway. LAGRANTO is applied offline on hourly COSMO output data on model levels. This has the advantage that trajectories can be calculated both forward and backward in time.

\section{Synoptic overview}

Typhoon Sinlaku (2008) developed east of the Philippines and quickly strengthened to typhoon intensity before it made landfall on the northern side of Taiwan on 14 September (Fig. 2). Because of the interaction with land and orography, Sinlaku weakened from a mature TC to a tropical storm and recurved. Subsequently, Sinlaku experienced increased vertical shear, and asymmetries in the TC structure developed, indicating the beginning of the transformation stage of ET. On its way to Japan, Sinlaku contained multiple convective bursts (Sanabia 2010), and when tracking 
(a)

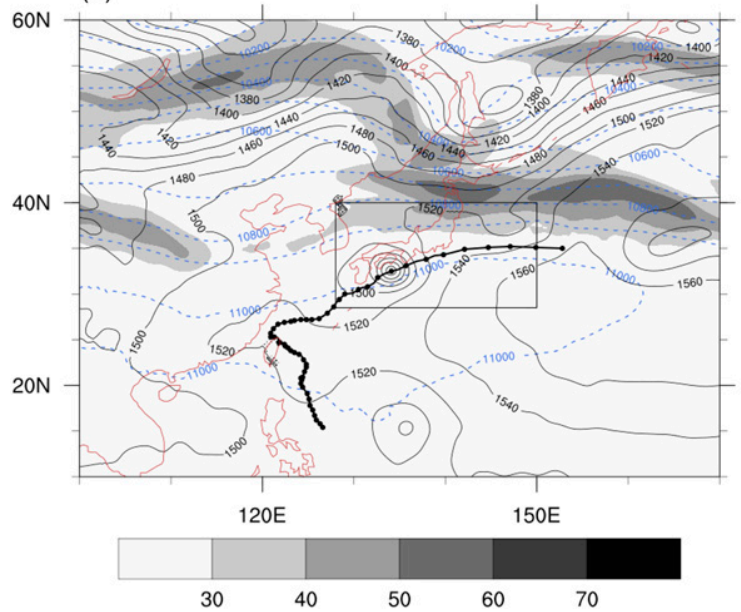

(b)

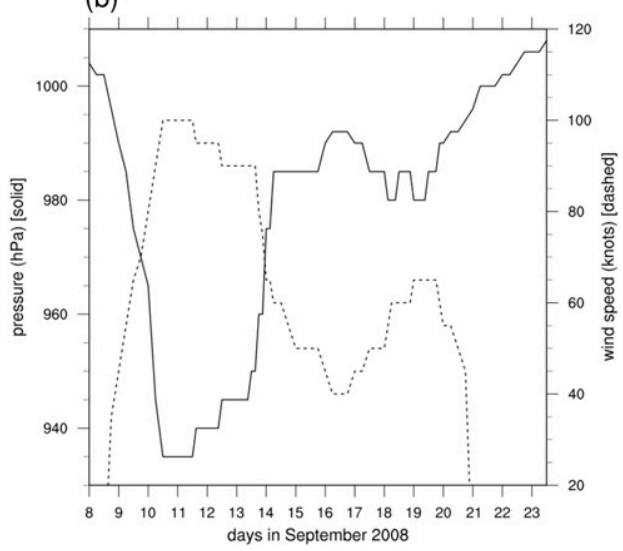

FIG. 2. (a) Best track of Sinlaku (2008; source: Japan Meteorological Agency). Black dots indicate the location of Sinlaku at 6-hourly interval from 8 to $23 \mathrm{Sep}$. Wind speed at $250 \mathrm{hPa}\left(\mathrm{m} \mathrm{s}^{-1}\right.$; shaded) and geopotential height (m) at 850 (black contours) and $250 \mathrm{hPa}$ (blue dashed contours) are shown from ECMWF research analysis data at 0000 UTC 19 Sep. The red contours represent coastlines. The black rectangle indicates the location of Fig. 4. (b) Best track central pressure (hPa; solid) and wind speed (kt; dashed; $1 \mathrm{kt}=0.5144 \mathrm{~m} \mathrm{~s}^{-1}$ ).

south of Japan, it unexpectedly reintensified to typhoon intensity instead of completing the transformation stage of ET (Foerster et al. 2014). At 0000 UTC 18 September, two convective rainbands wrapped into the center with a radius of $\sim 50 \mathrm{~km}$ (Kuo et al. 2012). An additional principal rainband was present $200 \mathrm{~km}$ east of the center. A secondary peak intensity was reached early on 19 September, with maximum wind speeds of over $65 \mathrm{kt}\left(\sim 130 \mathrm{~km} \mathrm{~h}^{-1}\right.$; Fig. 2b), and Sinlaku's eyewall structure resembled that of a mature TC in vertical wind shear (Foerster et al. 2014). The primary impact of vertical shear suggests that Sinlaku was at step 2 of the transformation stage of ET (Klein et al. 2000; Ritchie and Elsberry 2001). No evidence was found of the influence of midlatitude air, and Sinlaku was still warm cored at this time (Foerster et al. 2014). After the tropical reintensification, Sinlaku started its final decay while it continued to move close to the southern coast of Japan (Fig. 2a). On 20 September, Sinlaku started to interact with the midlatitude baroclinic zone (step 3 of ET's transformation stage), and major changes in the structure are dominated by inflowing cold dry air (Quinting et al. 2014). On the synoptic scale, Sinlaku was located southwest of a low-level low pressure system and an upper-level trough (Fig. $2 \mathrm{a} ; \sim 145^{\circ} \mathrm{E}$ ), which is an unfavorable atmospheric configuration for extratropical reintensification (Harr et al. 2000). Consequently, Sinlaku did not reintensify as an extratropical cyclone but decayed over the Pacific.

Sinlaku was one of the TCs that was investigated during The Observing System Research and Predictability Experiment (THORPEX) Pacific Asian Regional
Campaign (T-PARC). Measurements from three aircrafts provide a unique dataset for detailed analysis of structural development during ET. Between 0100 and 0600 UTC 19 September and between 0500 and 0900 UTC 20 September, the research aircrafts Naval Research Laboratory P-3 and the U.S. Air Force WC-130 flew through the central region to obtain measurements of the eyewall. The DLR-Falcon was operating in the environment northeast of the storm. Foerster et al. (2014) and Quinting et al. (2014) used the extensive dataset to describe the structure of Sinlaku during the transformation stage. Here, we employ high-resolution modeling, verified by these observations.

In the simulations, we aim to capture the ET phase of Sinlaku south of Japan, including the tropical reintensification phase, in a coherent numerical dataset. To test sensitivities on initial time and position, four simulations are performed, initiated at 0000, 0600, 1200, and 1800 UTC 18 September, on a domain of $24^{\circ}-50^{\circ} \mathrm{N}, 115^{\circ} \mathrm{E}-$ $180^{\circ}$. The simulations are verified against observational data, gridded by SAMURAI software (Bell et al. 2012; Foerster et al. 2014). The vortex structure was captured well for the simulation initialized at 1200 UTC 18 September (Fig. 3). It contains key features like a relatively compact wind field (Figs. 3a,c) and a warm moist tower throughout the troposphere (Figs. 3b,d). The high-resolution simulation initiated at 1200 UTC 18 September was therefore selected as the control simulation (CNTRL).

Sinlaku's ET is simulated from 1200 UTC 18 September to 1200 UTC 20 September in both the CNTRL and JFLAT setups, and the resulting tracks, based on the 
(a)

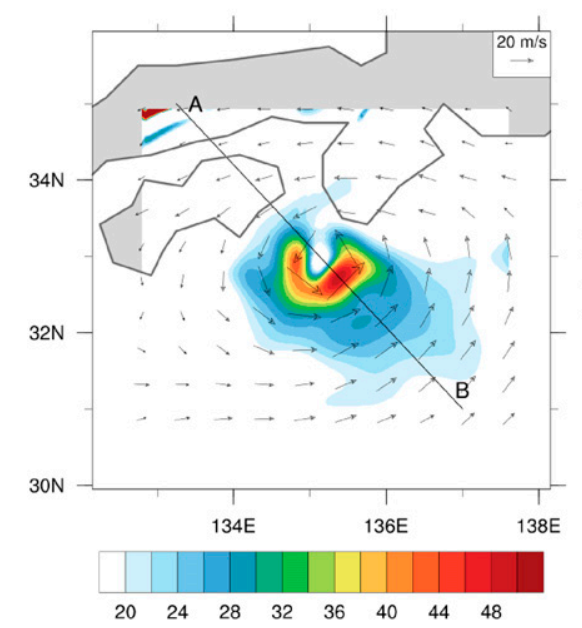

(c)

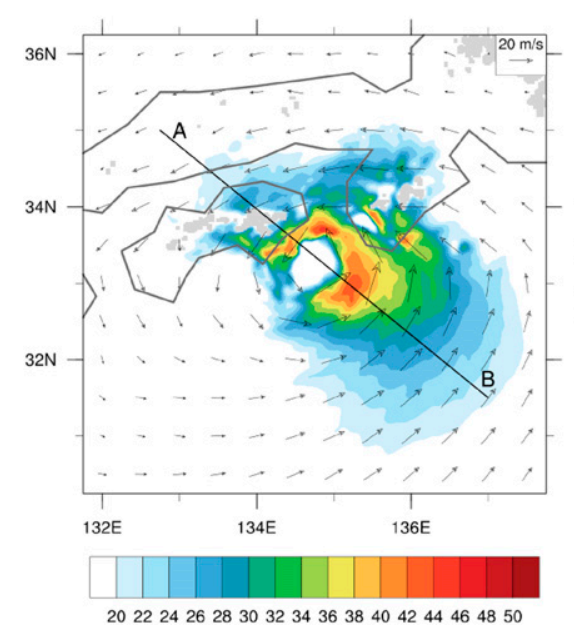

(b)

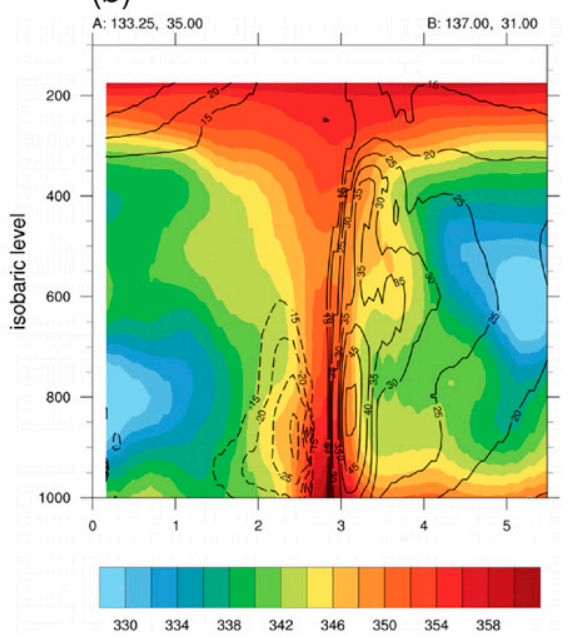

(d)

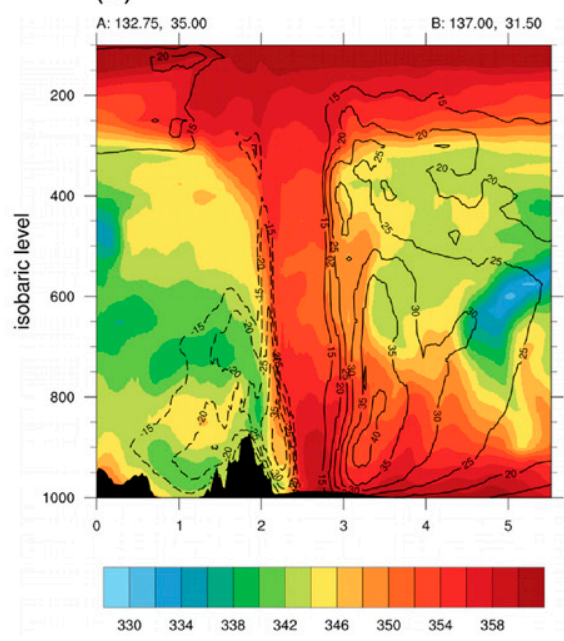

FIG. 3. (a),(c) Horizontal cross sections at $900 \mathrm{hPa}$ of wind speed $\left(\mathrm{m} \mathrm{s}^{-1}\right)$ and wind vectors and $(\mathrm{b}),(\mathrm{d})$ vertical cross sections $\left(x\right.$ axis; $\left.{ }^{\circ}\right)$ of equivalent potential temperature (K; shaded) and horizontal wind speed perpendicular to the cross section [black contours every $5 \mathrm{~m} \mathrm{~s}^{-1}$; solid (dashed) into (out of) the section] for (a),(b) SAMURAI data at 0400 and (c),(d) CNTRL at 0300 UTC 19 Sep. In (a) and (c) the gray contour represents the coastline of Japan, and in (c) and (d) gray and black areas in the simulated data represent orography; in (a) and (c) black lines show the location of (b) and (d) the cross sections.

location of minimum pressure at mean sea level, are similar to each other (Fig. 4). In the simulations, Sinlaku moves north of the best track and analysis track on 19 September and closer to Japan. Although the best track is, in general, assumed to be the best estimate of the cyclone development, it can have a significant bias, especially during ET (Kossin and Velden 2004). Observations indeed indicate a southerly bias of both the best track and the analysis data on 19 and 20 September (not shown). The pressure drop during the first hours of simulation reflects the model spinup (1200-1700 UTC 18 September). The additional pressure drop after
2300 UTC 18 September, however, reflects the tropical reintensification (Fig. 4). Differences in the intensity between CNTRL and JFLAT start from 0500 UTC 19 September: Sinlaku weakens in CNTRL but maintains a low central pressure in JFLAT. After 1700 UTC 19 September, when Sinlaku moves away from Japan, the central pressure decreases in CNTRL (Fig. 4), and Sinlaku intensifies as an extratropical cyclone. Based on the track and pressure evolution, as well as a more detailed verification against SAMURAI data and analysis data (Lentink 2017), we found CNTRL to accurately represent the ET of Sinlaku from 1800 UTC 18 September to 


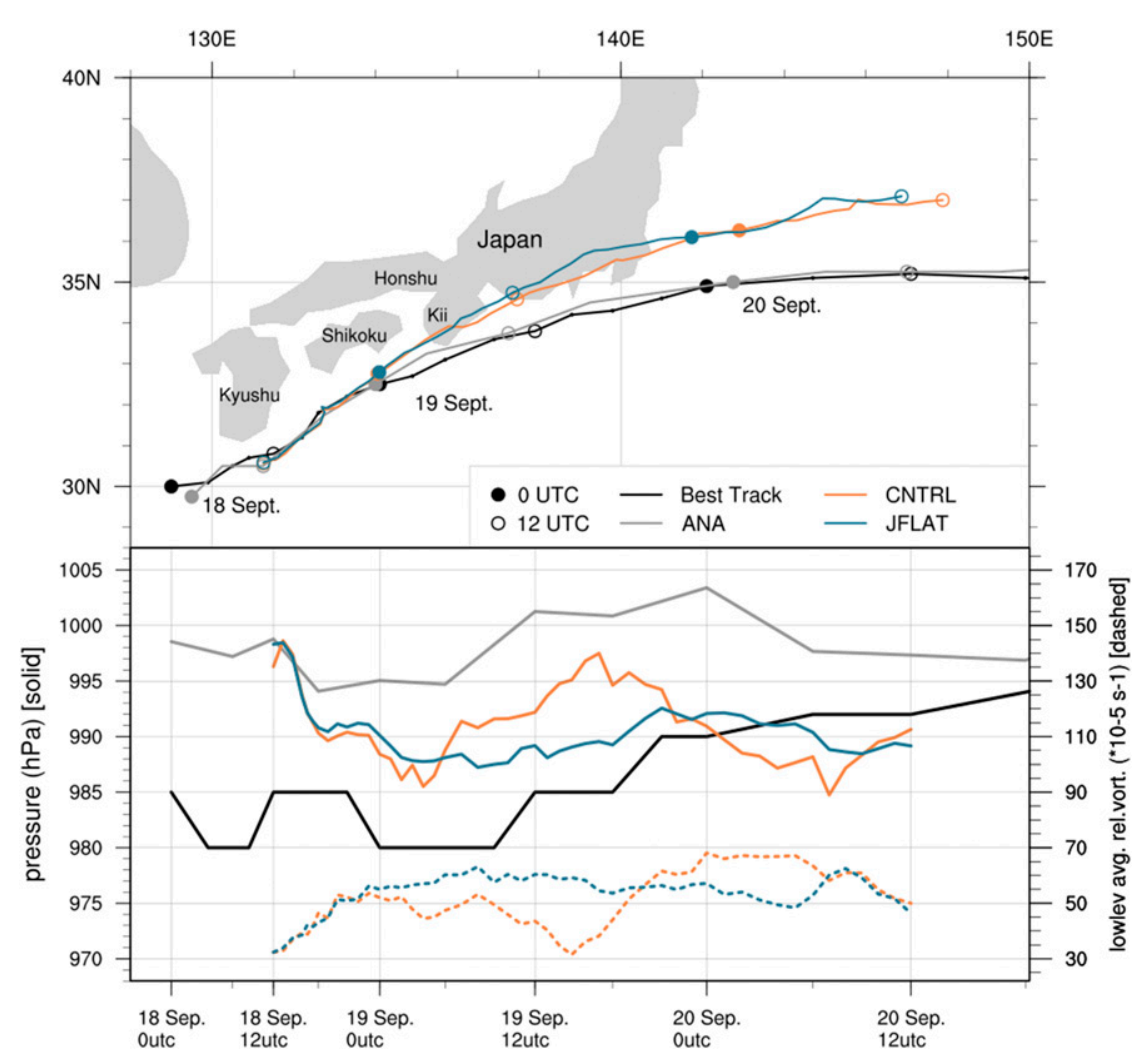

FIG. 4. (top) Location of Sinlaku's track according to the best track (black; source: Japan Meteorological Agency) and analysis data (gray) from 0000 UTC 18 Sep on and the control simulation (CNTRL; orange) and sensitivity simulation (JFLAT; blue) from 1200 UTC 18 Sep to 1200 UTC 20 Sep. (bottom) The accompanying central pressure (solid lines) is obtained from the minimum pressure at mean sea level $(\mathrm{hPa})$ for the analysis data and the simulations. Additionally, the mean 950-700-hPa relative vorticity $\left(\times 10^{-5} \mathrm{~s}^{-1}\right)$ in a circle with radius of $1^{\circ}$ from the center is shown for CNTRL and JFLAT (dashed lines).

1200 UTC 20 September on the environmental scale and up to 0600 UTC 19 September on the vortex scale.

\section{The impact of orography on the TC environment during ET}

In this section, the impact of orography on Sinlaku's ET is analyzed on an environmental scale, first from an Eulerian perspective and then from a Lagrangian perspective. The focus lies on the low-level temperature distribution and the blocking of air masses. The advection of cold air toward the cyclone is thereby a key feature because it marks the interaction of the TC with the baroclinic zone with subsequent frontal development. The lifting of warm and sinking of cold air masses indicates the onset of baroclinic energy conversion, due to which a cyclone may extratropically reintensify. This is the final phase of the transformation stage of ET. The following analysis is shown for the level of $925 \mathrm{hPa}$, at which the impact of orography on Sinlaku's structure is clearly seen. Above the orography, at a level of $700 \mathrm{hPa}$ and higher, the differences in cyclone structure that may be related to orography are small (not shown).

\section{a. Airmass characteristics}

At 0000 UTC 19 September, when Sinlaku underwent its tropical reintensification in CNTRL, it was embedded in warm air south of Japan (Fig. 5a). Colder air is present north of Japan and locally over orography. At this time, Sinlaku has a warm core that is almost aligned with the geopotential height center at 0000 UTC 19 September, suggesting an almost axisymmetric tropical system and no developing fronts yet. Six hours later, at 0600 UTC 19 September, cold air is seen locally west of Sinlaku's center (black rectangle in Fig. 5c), while the storm is still embedded in a subtropical air mass. Clear influences of the orography are seen in the form of air that is adiabatically warmed and dried (not shown) in downslope flow both south of Japan (around $32^{\circ} \mathrm{N}$, $133^{\circ} \mathrm{E}$ ) and north of Japan in an elongated area parallel 
(a) 0000 UTC 19 Sept., CNTRL

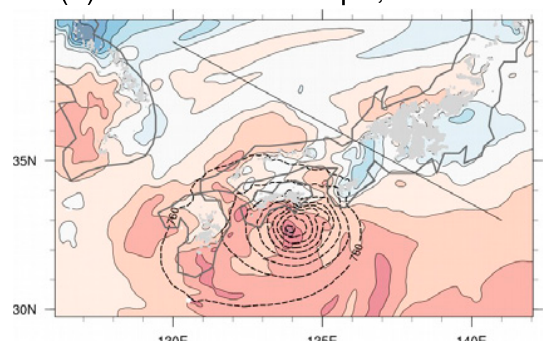

(c) 0600 UTC 19 Sept., CNTRL

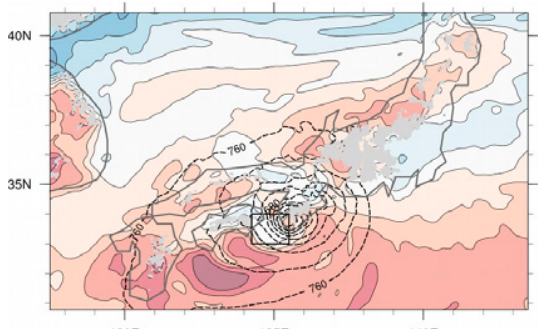

$130 \mathrm{E}$

(e) 1200 UTC 19 Sept., CNTRL

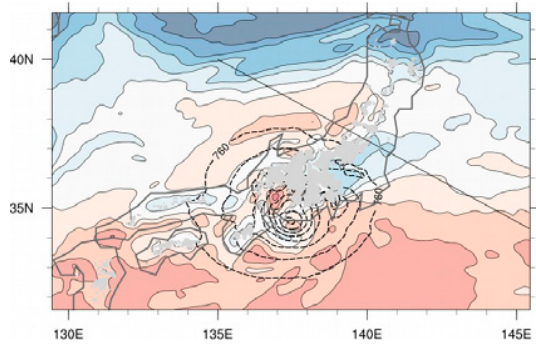

(g) 1800 UTC 19 Sept., CNTRL

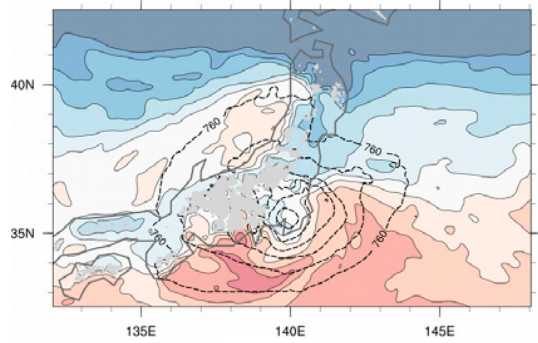

(i) 0000 UTC 20 Sept., CNTRL

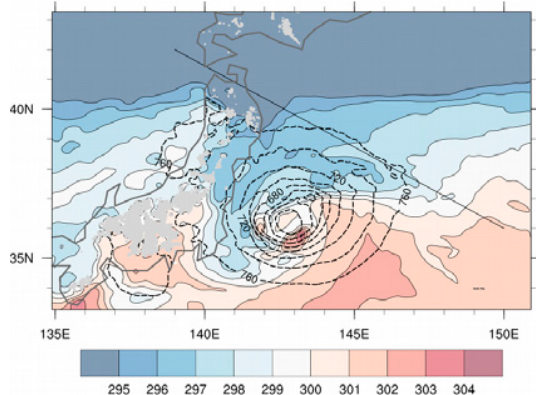

(b) 0000 UTC 19 Sept., JFLAT

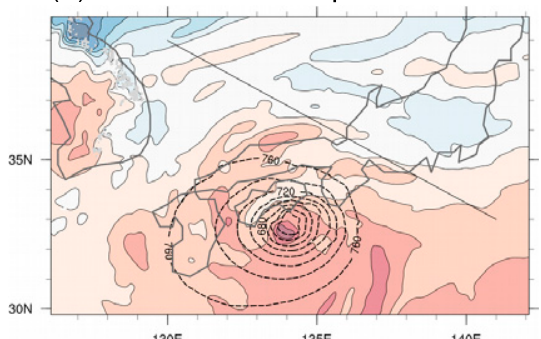

(d) 0600 UTC 19 Sept., JFLAT

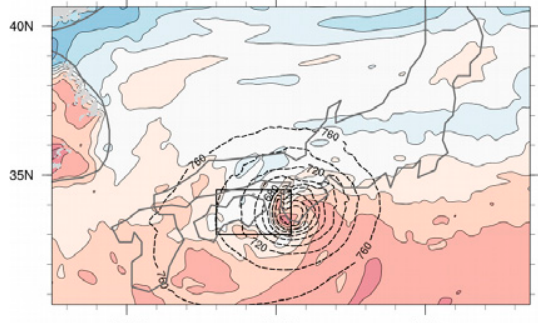

$135 \mathrm{E}$

$140 \mathrm{E}$

(f) 1200 UTC 19 Sept., JFLAT

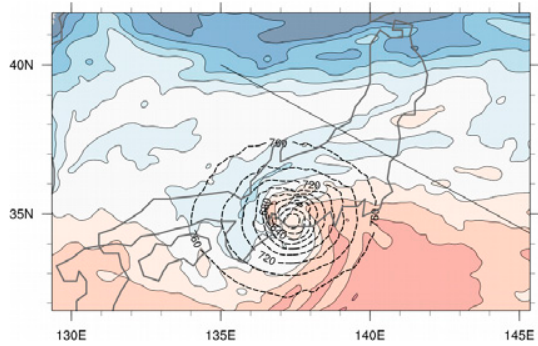

(h) 1800 UTC 19 Sept., JFLAT

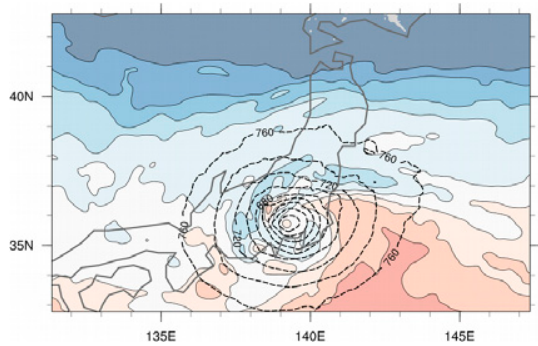

(j) 0000 UTC 20 Sept., JFLAT

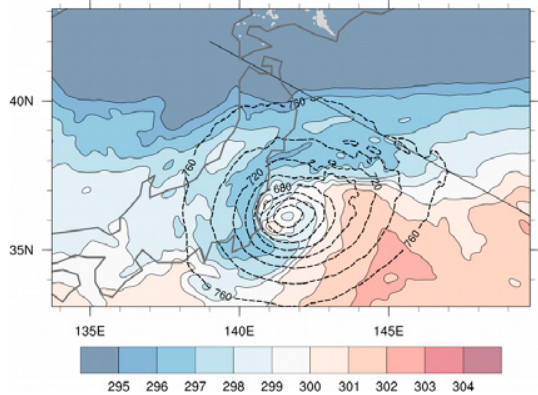

FIG. 5. Potential temperature (K; shaded) and geopotential height (up to $760 \mathrm{~m}$; dashed contours) at $925 \mathrm{hPa}$ at (a),(b) 0000, (c),(d) 0600, (e),(f) 1200, and (g),(h) 1800 UTC $19 \mathrm{Sep}$, and (i),(j) 0000 UTC 20 Sep for (left) CNTRL and (right) JFLAT. The gray contours represent coastlines, and gray areas represent orography. The black lines indicate the starting lines of trajectories in Fig. 6, and the black rectangles at 0600 UTC 19 Sep indicate the starting areas of trajectories in Fig. 7. 
to the mountains (around $37.5^{\circ} \mathrm{N}, 138.5^{\circ} \mathrm{E}$; Fig. 5c). Sinlaku's environment cools when Sinlaku moves northeastward, but it is still relatively warm, compared to the air north of the midlatitude baroclinic zone approaching from the north (around $40^{\circ} \mathrm{N}$; Fig. 5e). Meanwhile, an additional but minor horizontal temperature gradient is seen east of Japan at $35^{\circ} \mathrm{N}$, at the same latitude as where Sinlaku is present, but the cold air is blocked by the orography (Fig. 5e). Cold air is not advected into the cyclonic system until Sinlaku is at the eastern border of the orography at 1800 UTC 19 September (Fig. 5g). In the next $6 \mathrm{~h}$, as Sinlaku moves away from Japan and over the open ocean, colder midlatitude air is free to move equatorward (Fig. 5i). The interaction with the baroclinic zone starts, and a clear cold and warm front can be seen to the southwest and northeast of the cyclone center, respectively.

In JFLAT, the synoptic-scale low-level atmospheric situation during tropical reintensification (0000 UTC 19 September; Fig. 5b) is quite similar to CNTRL. Differences start a few hours later, at 0600 UTC 19 September, when no adiabatic warming downstream of orography is observed and when cold air enters the center region on the west side of the cyclone (black rectangle in Fig. 5d). This cold air is not only present locally, as in CNTRL, but it is also linked to a larger area of cold air northeast of the cyclone $\left(35^{\circ}-38^{\circ} \mathrm{N}\right.$, $133^{\circ}-143^{\circ} \mathrm{E}$; Fig. $5 \mathrm{~d}$ ), which is not the midlatitude air yet. In the absence of an orographic barrier, the cold air continues to be advected toward Sinlaku in the next $12 \mathrm{~h}$ and wraps around the center (Figs. 5f,h). At these times, a warm and cold front can already be observed between air masses with potential temperatures $\theta<$ 300 and $\theta>300 \mathrm{~K}$, although the actual midlatitude baroclinic zone is still located farther north (around $40^{\circ} \mathrm{N}$ ). The temperature distribution is rather similar again for both simulations at 0000 UTC 20 September, when Sinlaku has moved away from the orographic barrier in CNTRL (Figs. 5i,j).

To summarize, Sinlaku gradually changes from a warm-core cyclone into a cold-core cyclone in the absence of orography (JFLAT) and resembles a classic ET. In this case, Sinlaku could develop under baroclinic energy conversion and maintain its intensity (Fig. 4). The first advection of cold air originates from a mesoscale region northeast of the cyclone, followed by the advection of synoptic-scale midlatitude air $18 \mathrm{~h}$ later. In the presence of orography (CNTRL), on the other hand, a substantial amount of cold air cannot reach Sinlaku. It therefore preserves its warm core for a relatively long time, while slowly decreasing its intensity. ET then occurs quite abruptly when Sinlaku moves away from the orographic barrier. This shows that the final phase of the transformation stage of ET, in which the cyclone interacts with colder air, is, in the case of Sinlaku, postponed under influence of orographic blocking.

\section{b. Orographic flow blocking}

We now examine air parcel trajectories to gain further insight into the orographic flow blocking. To see the lowlevel advection of air masses, trajectories were started at $925 \mathrm{hPa}$ on lines crossing Japan downstream of Sinlaku's track and computed $12 \mathrm{~h}$ forward (Fig. 6). During tropical reintensification in CNTRL, low-level cold dry air moves north of the Japanese mountains (Fig. 6a). South of Japan, Sinlaku (blue cross in Fig. 6a) was located in a subtropical warm moist air mass and protected from the intrusion of cold dry air. However, a local area of air with a low equivalent potential temperature $\theta_{e}$ was present south of Japan at $34^{\circ} \mathrm{N}, 138^{\circ} \mathrm{E}$. This local low- $\theta_{e}$ air was advected toward Sinlaku within a few hours' time around 0600 UTC 19 September, when Sinlaku was located at $33.5^{\circ} \mathrm{N}, 136^{\circ} \mathrm{E}$ (directly between the blue $x$ and $o$ in Fig. 6a). Together with dry air inflow from land, it contributes to the decrease in $\theta_{e}$ of Sinlaku's environment at 1200 UTC 19 September, which has no clear subtropical character anymore (low $-\theta_{e}$ air around the blue $\mathrm{x}$ in Fig. 6c). The cold midlatitude air, however, cannot reach Sinlaku and flows around the orography. When Sinlaku moves toward the eastern border of the orography $\left(35^{\circ} \mathrm{N}\right.$, $140^{\circ} \mathrm{E}$; Fig. $6 \mathrm{c}$ ), a few air parcels penetrate into the cyclonic system. This interaction with cold dry air develops further when Sinlaku moves eastward, away from Japan at 0000 UTC 20 September (Fig. 6e). The midlatitude air is now free to move equatorward and is able to encircle Sinlaku's center.

The synoptic-scale distribution of relatively low- and high- $\theta_{e}$ air is quite similar in CNTRL and JFLAT (gray shades in Fig. 6). The differences lie in the advection of the air. In the absence of orography, relatively cold dry air is advected across Japan into Sinlaku's circulation already shortly after tropical reintensification (Fig. 6b). The air does not arrive from the baroclinic zone but rather from a local area with low $\theta_{e}$ values to the northeast of the center (Fig. $6 \mathrm{~b} ; 34.5^{\circ} \mathrm{N}, 138^{\circ} \mathrm{E}$ ). This behavior is similar to the local cold air advection at 0600 UTC 19 September south of Japan for CNTRL (Fig. 6a) with the difference that whereas Sinlaku in CNTRL is again protected from cold air inflow at 1200 UTC 19 September, the colder air in JFLAT could continue to move freely toward the cyclone (Fig. 6d). Farther eastward, at 0000 UTC 20 September, the inflow of colder air has a midlatitude character with very low $\theta_{e}$ originating from a broad area. The trajectory 
(a) 0000 UTC 19 Sept., CNTRL

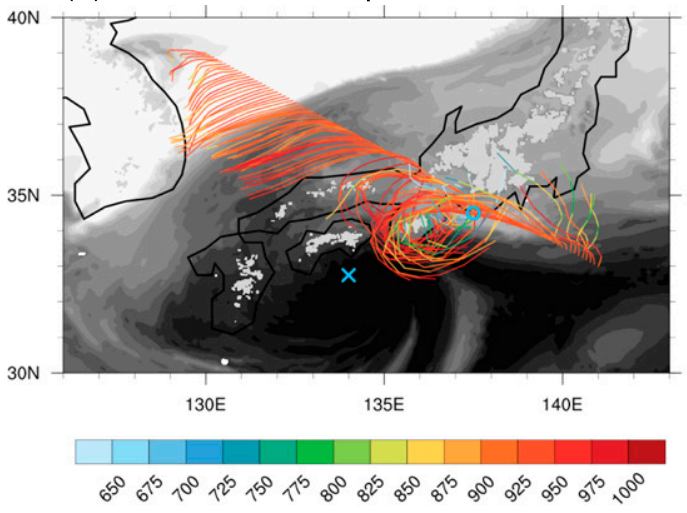

(c) 1200 UTC 19 Sept., CNTRL

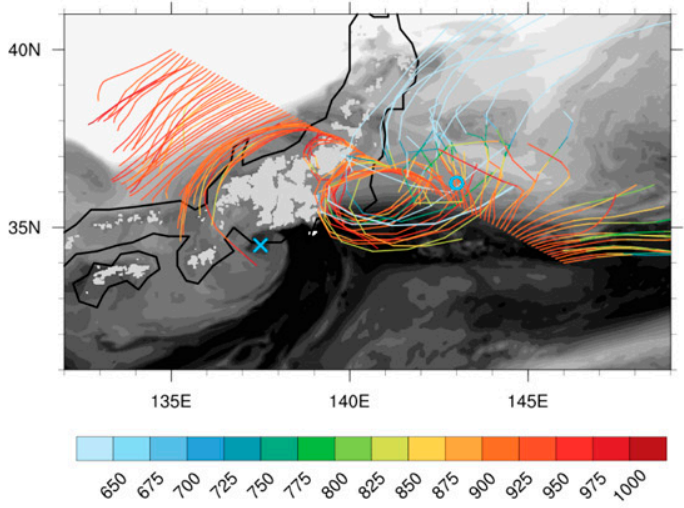

(e) 0000 UTC 20 Sept., CNTRL

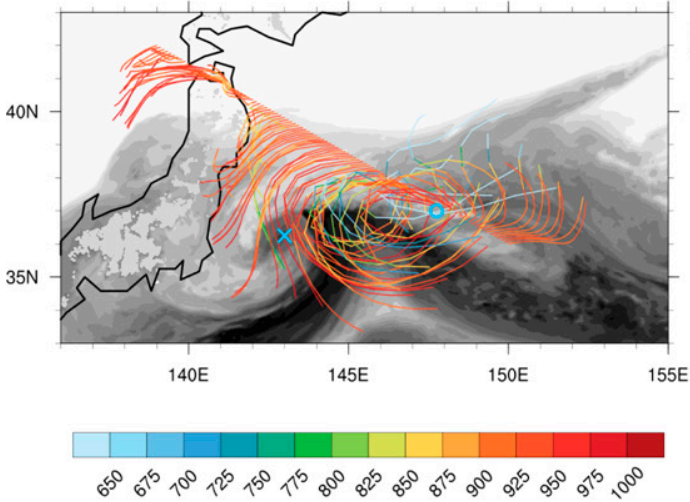

(b) $0000 U T C 19$ Sept., JFLAT

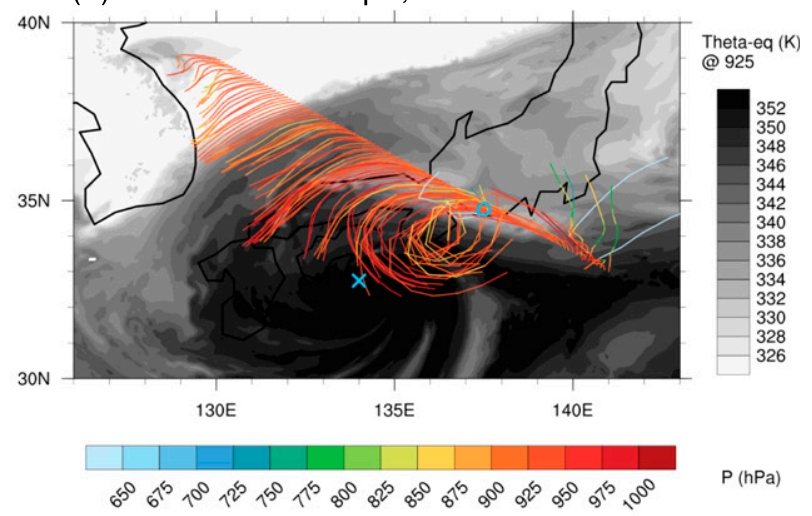

(d) 1200 UTC 19 Sept., JFLAT

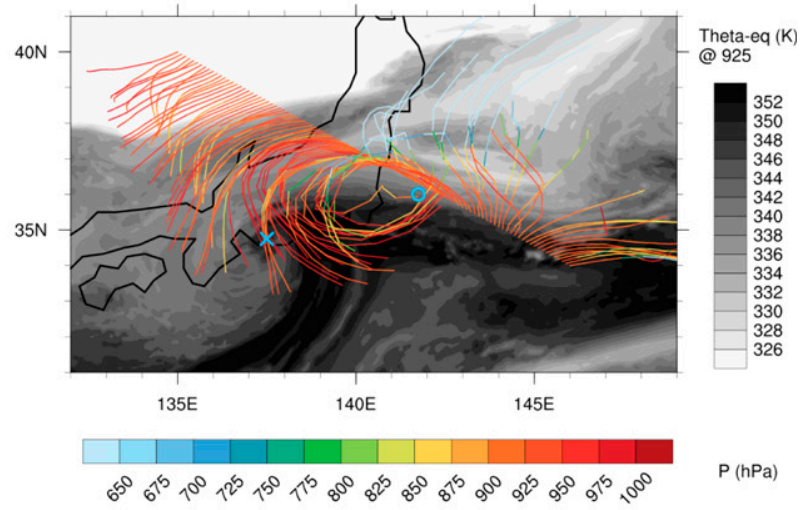

(f) 0000 UTC 20 Sept., JFLAT

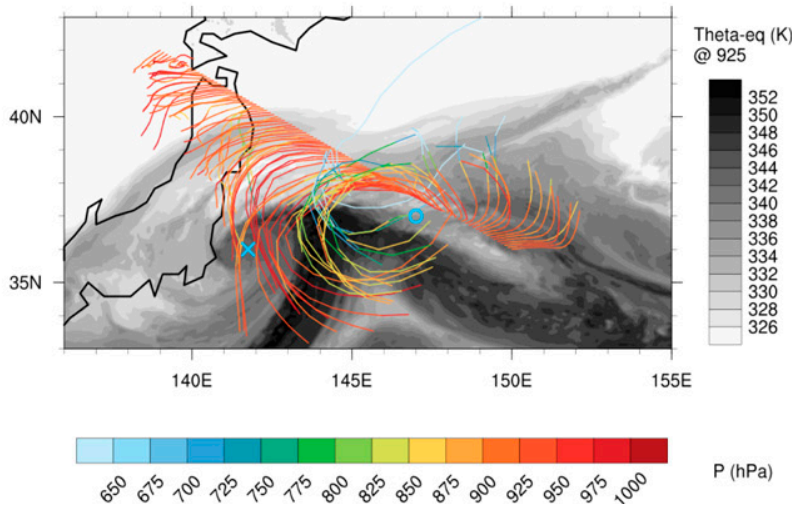

FIG. 6. The 12-h forward trajectories (100) starting every $\sim 0.125^{\circ}$ on a northwest-southeast line crossing Japan (black lines in Fig. 5) at $925 \mathrm{hPa}$ at (a),(b) 0000 and (c),(d) 1200 UTC 19 Sep, and (e),(f) 0000 UTC 20 Sep for (left) CNTRL and (right) JFLAT. The colors show the pressure $(\mathrm{hPa})$ along the trajectories, and the gray shades represent $\theta_{e}(\mathrm{~K})$ at $925 \mathrm{hPa}$ at trajectory starting time. The location of minimum mean sea level pressure of Sinlaku is marked by a blue cross (at trajectory start) and circle (at trajectory end). The black contours represent coastlines, and gray areas in Japan represent orography.

pattern looks similar for JFLAT and CNTRL at this time (Figs. 6e,f), although the cyclonic system is still more compact in CNTRL (Fig. 5i; additionally indicated by the smaller radius of circulating trajectories in Fig. 6e); therefore, the inflow of cold air can occur on a smaller radius, penetrating more quickly into the center.
The trajectory analysis confirmed that environmental flow is deviated around the Japanese orography and can only reach Sinlaku once it moves away from Japan. Therefore, the orographic flow blocking delays the ET of Sinlaku, and ET progresses suddenly when Sinlaku moves past the barrier. 
In contrast, ET could occur gradually in the absence of orography.

\section{The impact of orography on the cyclone development during ET}

In this section, the impact of orography on Sinlaku's ET is analyzed on the vortex scale. First, local cold air advection that occurs before the interaction with the synoptic-scale midlatitude air is analyzed. Second, the vortex development is compared to mechanisms known from mature TCs near orography.

\section{a. Local cold air advection}

Tropical reintensification ended abruptly at 0600 UTC 19 September in CNTRL, according to the central pressure (Fig. 4). At this time, cold low- $\theta_{e}$ air was advected toward the west side of Sinlaku near the cyclone center (black rectangle in Fig. 5c), causing a pressure rise without a decrease in vorticity (Fig. 4). This local cold air inflow influenced the subtropical warm moist air in which Sinlaku resided during tropical reintensification in the previous hours and is therefore analyzed in more detail by the use of trajectories. Backward trajectories that are started in the colder air $(\theta<300 \mathrm{~K}$ at $925 \mathrm{hPa}$; black rectangle in Fig. 5c) west of Sinlaku in CNTRL can be split into a northern branch (62\% of 343 trajectories; Fig. 7a) and a southern branch (33\% of 343 trajectories; Fig. 7b), based on their source region north or south of $33^{\circ} \mathrm{N}$ and their original $\theta_{e}$ value lower than or higher than $344 \mathrm{~K}$, respectively. A minority of trajectories originated and stayed near the center of Sinlaku $(1 \%)$ or had their source region just north of $33^{\circ} \mathrm{N}$ with an original $\theta_{e}$ value higher than $344 \mathrm{~K}(4 \%)$. The latter two categories are neglected here. In JFLAT, the majority of trajectories can be divided in the same branches with similar properties, although now most trajectories are found in the southern branch (61\% of 936 trajectories; Fig. $7 d$ ) instead of in the northern branch $(25 \%$ of 936 trajectories; Fig. 7c), and the difference between the branches is less evident because there is a substantial number of trajectories originating north of $33^{\circ} \mathrm{N}$ with $\theta_{e}>344 \mathrm{~K}(13 \%)$. Here, no air parcels originate near the center. The average behavior of the northern and southern branches will be discussed based on the statistical development of the bundles of trajectories over time for CNTRL (Figs. 8a-c and $8 \mathrm{~d}-\mathrm{f}$, respectively).

The northern branch of air parcels originates near Japan and has relatively low initial $\theta_{e}$ values in both simulations (Figs. 7a,c). The air parcels are located below a precipitation field (white lines in Fig. 7) that is associated with the asymmetric cloud shield that developed before tropical reintensification took place and is associated with
Sinlaku's ET (not shown). In CNTRL, these air parcels experience evaporative cooling, as indicated by descent (Fig. 8a), a decrease in potential temperature (Fig. 8b), and an increase in specific humidity (Fig. 8c). The air parcels are advected westward along the coast and then over land around the mountains of the Kii Peninsula (Fig. 7a; the names of topographic locations are given in Fig. 1). Nevertheless, they are forced to rise over local hills (Fig. 8a; $t=-3$ to $t=0$ ). There is still an increase in water vapor from evaporating precipitation (Fig. 8c), which is now associated with Sinlaku's principal rainband that propagated over the Kii Peninsula (red line in Fig. 7b). Despite evaporation, the air parcels unexpectedly warm again (Fig. 8b). The warming, as well as the increase in specific humidity, might be influenced by local mixing of the ascending air parcels with warm and moist subtropical air near the cyclone center. In the last hour, these air parcels are channeled over the sea between the mountains of Shikoku and the Kii Peninsula (Fig. $7 \mathrm{a} ; 34^{\circ} \mathrm{N}, 135^{\circ} \mathrm{E}$ ) and finally arrive west of Sinlaku. They have a lower $\theta_{e}$ than the environment in which Sinlaku resided (Fig. 6a), although their $\theta_{e}$ is higher than they originally had, due to the gain in water vapor (Fig. 7a). In JFLAT, the process is similar (accompanying statistics not shown), except that the low $-\theta_{e}$ air is not forced between the mountains of Shikoku and the Kii Peninsula in the last hour. The cold air is therefore distributed over a larger area west of Sinlaku's center (Fig. 7c).

The southern branch of air parcels originates southeast of Sinlaku in both simulations (Figs. 7b,d) at lower levels (Fig. 8d) in an initially precipitation-free area. These air parcels are of subtropical origin, with a higher initial potential temperature and water vapor content than the northern branch (Figs. 8e,f). In CNTRL, when these air parcels are near the orography of the Kii Peninsula and near a convective area, they ascend while the potential temperature increases and water vapor is lost, arguably by condensation (at $t=-3$ in Figs. 8d-f). At $t=-2$, however, they arrive near the area of Sinlaku's principal rainband and thus are influenced by strong precipitation (Fig. 7b). Evaporative cooling (Figs. 8e,f) causes the air parcels to descend suddenly (Fig. 8d). They then turn cyclonically to arrive as relatively cold air to the west of Sinlaku (Fig. 7b). The sudden evaporative cooling and sinking in the last $2 \mathrm{~h}$ is not observed for the northern branch because it was mainly located in the area of weaker precipitation (Figs. 7a, 8a-c). Again, the processes are similar for JFLAT, but in the absence of orography, the trajectories are distributed over a larger area in the last few hours, and more air parcels that are evaporatively cooled are able to reach the vicinity of the cyclone (Fig. 7d). 
(a) CNTRL, northern branch

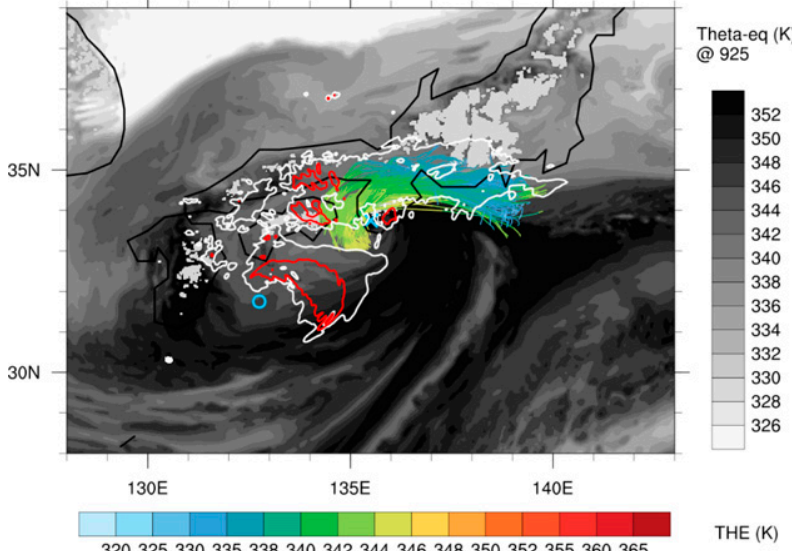

(c) JFLAT, northern branch

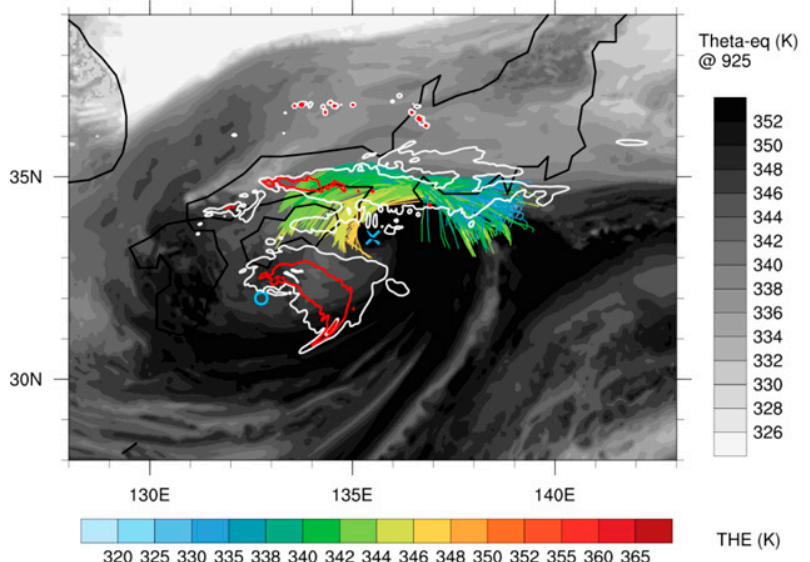

(b) CNTRL, southern branch

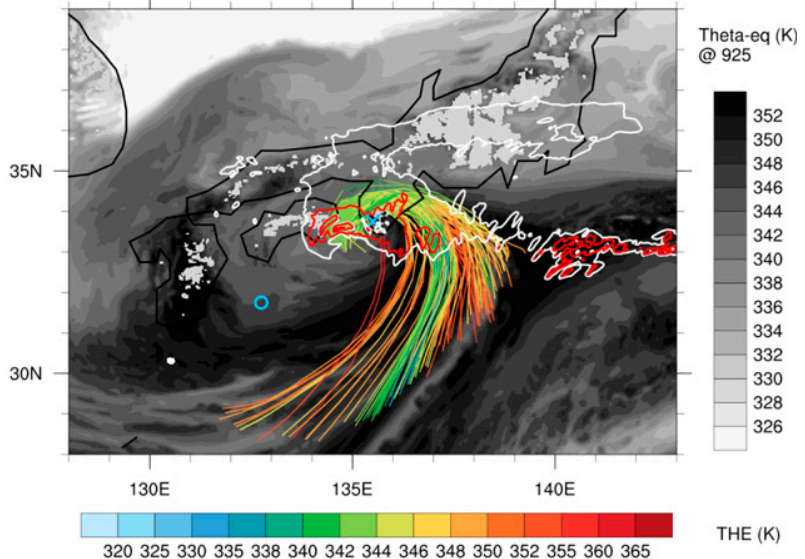

(d) JFLAT, southern branch

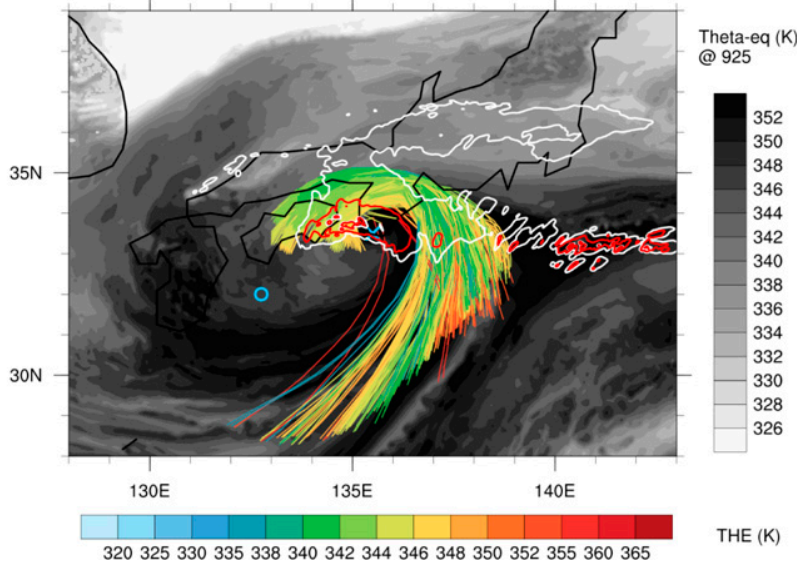

FIG. 7. The 12-h backward trajectories starting at 0600 UTC 19 Sep in the relatively cold air $(\theta<300 \mathrm{~K})$ at $925 \mathrm{hPa}$ west of the cyclone center (see rectangles in Figs. 5c and 5d) at a horizontal distance of every $5 \mathrm{~km}$ for (a),(b) CNTRL and (c),(d) JFLAT. The resulting trajectory branches are selected based on their origin and original temperature at $1800 \mathrm{UTC} 18 \mathrm{Sep}$ (a), (c) north of $33^{\circ} \mathrm{N}, \theta_{e}<344 \mathrm{~K}$ and (b),(d) south of $33^{\circ} \mathrm{N}, \theta_{e}>344 \mathrm{~K}$. The colors represent $\theta_{e}(\mathrm{~K})$ along the trajectories, and the gray shades represent $\theta_{e}(\mathrm{~K})$ at $925 \mathrm{hPa}$ at 0600 UTC 19 Sep. The white and red contours are the outlines of hourly precipitation exceeding 0.5 and $10 \mathrm{~mm}$, respectively, at (a),(c) 2000 UTC 18 Sep and (b),(d) 0300 UTC 19 Sep. The location of minimum mean sea level pressure of Sinlaku is marked by a blue cross (at trajectory start; 0600 UTC 19 Sep) and circle (at trajectory end; 1800 UTC 18 Sep). The black contours represent coastlines, and gray areas in Japan represent orography.

Overall, it is seen that air parcels are evaporatively cooled below Sinlaku's own asymmetric precipitation field. This process is similar to what Riemer et al. (2010, 2013) describe for a mature TC: asymmetric precipitation associated with a shear-induced rainband causes relatively low- $\theta_{e}$ air in the boundary layer that flows into the eyewall and decreases the energy cycle of the TC. This leads to the hypotheses that 1) the first interaction of the cyclone with colder air occurs with the mesoscale evaporatively cooled air under the influence of vertical shear before the TC interacts with the synoptic-scale midlatitude air north of the baroclinic zone, and 2) this evaporatively cooled air is blocked by the orography of Japan, and its inflow into Sinlaku is delayed. Only during a time interval of a few hours, when local orography was favorable, could cold air be advected toward Sinlaku.

\section{b. Development of the vortex structure}

Four mechanisms that play a role in the structural change of landfalling mature TCs, as described in the introduction, are considered for ET: 1) orographically induced convergence, 2) dry air inflow from land, 3) differential friction, and 4) track deflection toward the area of maximum diabatic generation of PV anomalies. Subsequently, additional structural changes related to orography are analyzed as well.

Starting with the orographically induced convergence (mechanism 1), Tang and Chan (2014) mentioned that 
(a) CNTRL, northern branch, $p$

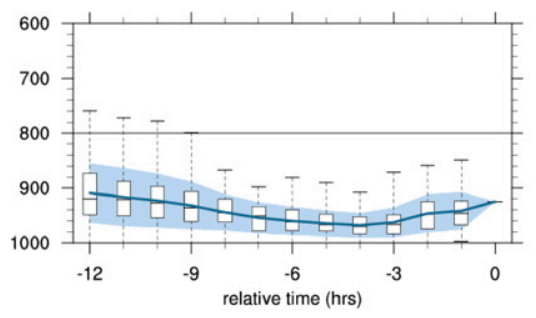

(d) CNTRL, southern branch, $p$

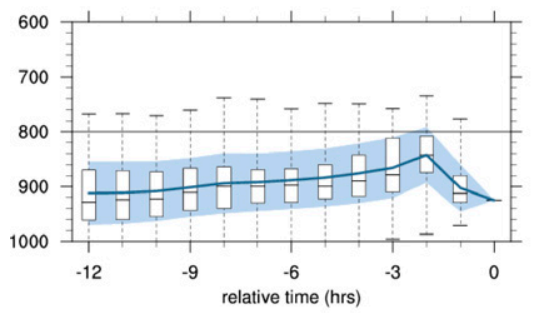

(b) CNTRL, northern branch, $\theta$

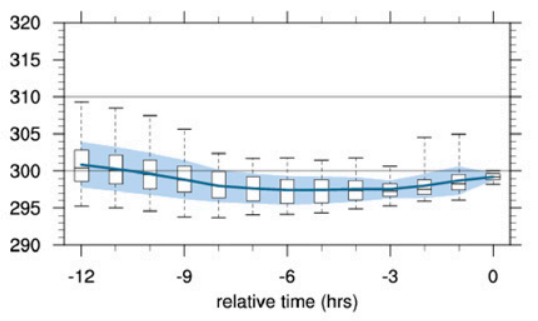

(e) CNTRL, southern branch, $\theta$

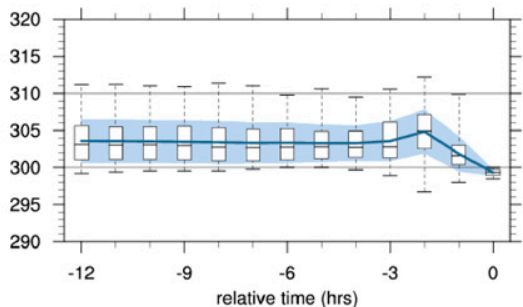

(c) CNTRL, northern branch, $q_{v}$

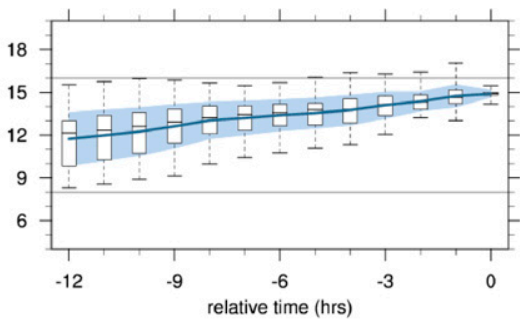

(f) CNTRL, southern branch, $q_{v}$

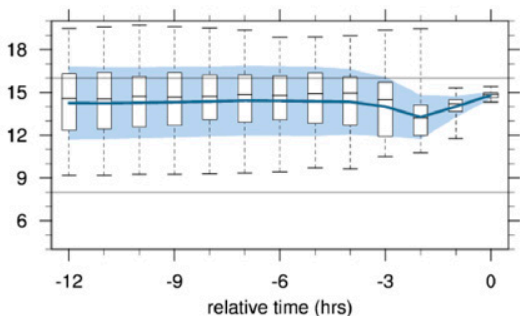

FIG. 8. Statistical development corresponding to the 12-h backward trajectories of the (a)-(c) northern branch (Fig. 7a) and (d)-(f) southern branch (Fig. 7b) of cold air advection near the center of Sinlaku at 0600 UTC 19 Sep in the CNTRL simulation. Shown are (a),(d) pressure (hPa), (b),(e) potential temperature (K), and (c),(f) specific humidity $\left(\mathrm{g} \mathrm{kg}^{-1}\right)$ along the trajectories on the $y$ axis and time (h) on the $x$ axis, where $t=0$ is the start time of the trajectories. Hourly box-and-whisker plots show the maximum, minimum, 25\% and $75 \%$ percentiles, and median of the trajectory ensemble. The blue line and shading represent the average and standard deviation, respectively. Additional horizontal black lines are added as a reference value.

the larger-scale cyclone circulation over orography induces a vortex stretching and, consequently, a positive vorticity anomaly where the air is advected offshore, away from the mountains. As a result, cyclonic deflection of the airflow, which is parallel to the mountains, causes an area of convergence near the cyclone. For Sinlaku, a similar situation is observed. At 0300 UTC 19 September, an area of enhanced positive relative vorticity is found south of the orography at $32.75^{\circ}-33.5^{\circ} \mathrm{N}, 133.25^{\circ}-134.0^{\circ} \mathrm{E}$ (Fig. 9a). Negative relative vorticity is found directly east of it $\left(33.0^{\circ} \mathrm{N}, 134.2^{\circ} \mathrm{E}\right)$, at the location where the cyclonic flow was partly over land and channeled between the circulation center and the orography. The positive and negative relative vorticity anomalies deflect the flow so that the streamlines converge (Fig. $9 \mathrm{a} ; 33.0^{\circ} \mathrm{N}, 134.2^{\circ} \mathrm{E}$ ), and a convergence zone similar to that of Tang and Chan (2014, their Fig. 8c) is indeed found at this location (Fig. 9c; $33.0^{\circ} \mathrm{N}, 134.2^{\circ} \mathrm{E}$ ). The resulting precipitation area, however, is a minor effect in comparison to the rainband and accounts for an area of weak precipitation up to $3 \mathrm{~mm} \mathrm{~h}^{-1}$ (Fig. 7b). In JFLAT, this pattern is not observed (Fig. 9b), and both the convergence and precipitation areas are mainly found in the rainband northeast of the center (Figs. 9d, 7d).

Dry air from land (mechanism 2) is seen in the outer circulation of Sinlaku in the form of downslope adiabatically warmed air (Fig. $\left.5 \mathrm{c} ; 31.5^{\circ}-33.5^{\circ} \mathrm{N}, 132^{\circ}-135^{\circ} \mathrm{E}\right)$.
However, trajectories reveal that the dry air does not reach the inner core of Sinlaku (not shown). The dry air moves parallel to Sinlaku at lower levels and stays in its outer circulation to the south and southwest of the center, because the speed of the dry air mass is less than or equal to the translation speed of the storm. Moist, high $-\theta_{e}$ air lies near the surface below the low- $\theta_{e}$ downslope air (not shown), but without a clear triggering mechanism, this potential instability does not have an effect on the vertical motion field.

The effect of differential friction on ascending motion on the onshore side (mechanism 3) is not observed because the effect of orography was dominant. Also, a clear track deflection (mechanism 4) is not observed. During the period 1800 UTC 18 September to 0600 UTC 19 September, Sinlaku moved northeastward, with a translation speed that increases from 8 to $9 \mathrm{~m} \mathrm{~s}^{-1}$. The direction and speed of the track is similar to the $950-250-\mathrm{hPa}$ average environmental flow (Lentink 2017). Additionally, the tracks are similar in case of orography and in absence of orography (Fig. 4). Sinlaku's track is therefore dominated by the environmental steering flow.

In addition to these four selected mechanisms, as known from literature about mature TCs, other structural changes related to orography are observed. Orographic lifting is more often seen for ET, related to an asymmetric precipitation field in the environment of the 
(a) CNTRL

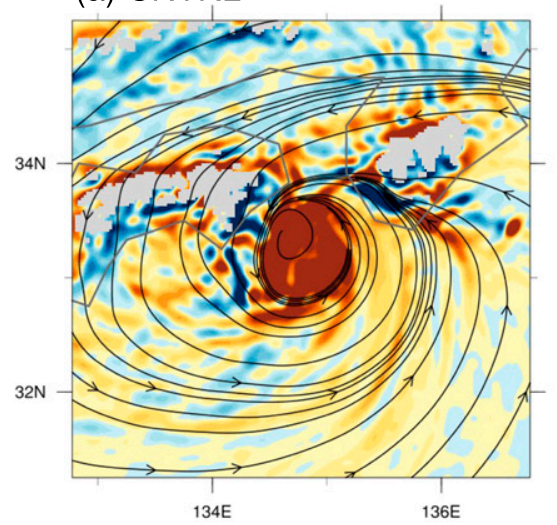

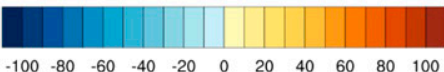

(c) CNTRL
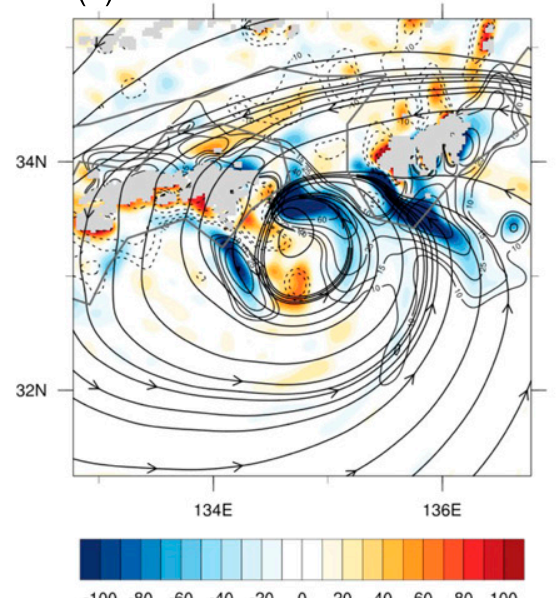

(e) CNTRL

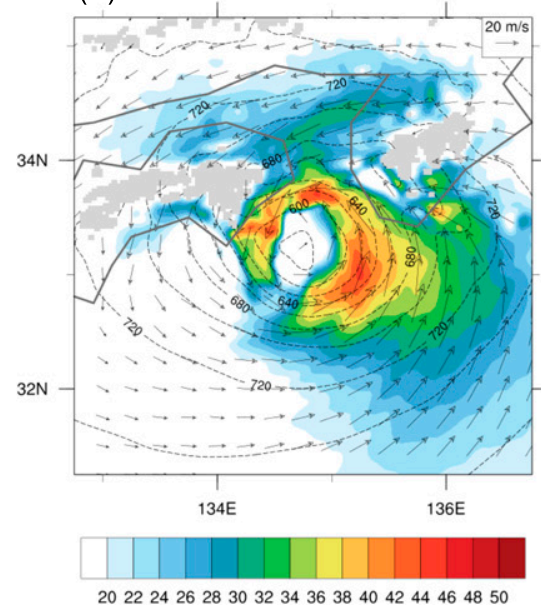

(b) JFLAT
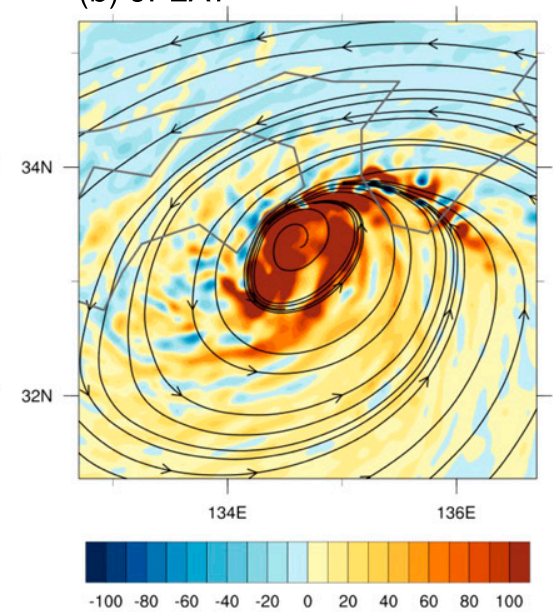

(d) JFLAT

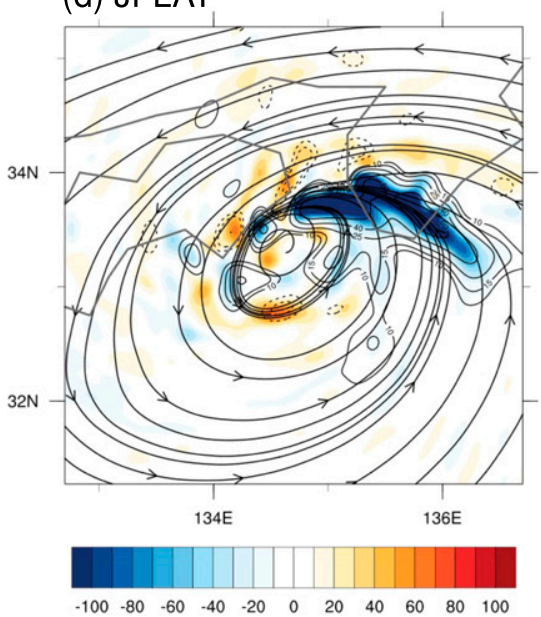

(f) JFLAT

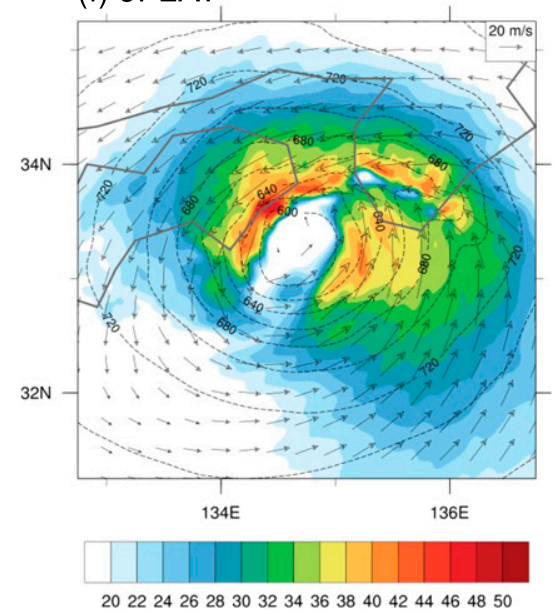

FIG. 9. (a),(b) Relative vorticity $\left(\times 10^{-5} \mathrm{~s}^{-1}\right.$; shaded) and streamlines; (c),(d) divergence $\left(\times 10^{-5} \mathrm{~s}^{-1}\right.$; shaded), vertical motion ( $\mathrm{cm} \mathrm{s}^{-1}$; upward: solid contours, downward: dashed contours), and streamlines; and (e),(f) horizontal wind speed ( $\mathrm{m} \mathrm{s}^{-1}$; shaded) and geopotential height (m; dashed contours) for (left) CNTRL and (right) JFLAT at $925 \mathrm{hPa}$ at 0300 UTC 19 Sep. The gray contours represent coastlines, and gray areas represent orography. 
cyclone (e.g., Hart and Evans 2001; Sinclair 1993). In this study, Sinlaku experiences orographic lifting on the vortex scale. The convergence area associated with the rainband in CNTRL is split into two areas with enhanced updrafts just upstream of the Kii Mountains and the Shikoku Mountains (Fig. 9c; $33.5^{\circ} \mathrm{N}, 135.8^{\circ} \mathrm{E}$, and $33.5^{\circ} \mathrm{N}, 134.7^{\circ} \mathrm{E}$, respectively). In the absence of orography, the area of enhanced convergence and updrafts is still one area, stretched along the advancing rainband (Fig. 9d). Regarding the low-level cyclonic wind field, Sinlaku has tropical characteristics in CNTRL, being relatively symmetric and compact (Fig. 9e). The compact wind field in CNTRL might be explained partly by channeling of air between the cyclone center and orography, and partly by the blocking of inflowing cold air. In JFLAT, cold air could be advected toward the center, and the wind field indicates characteristics of ET with an asymmetric and widening circulation (Fig. 9f). Therefore, Sinlaku could maintain its TC-like wind field structure for a longer period in the presence of orography.

To summarize, two of the four tested mechanisms of structural changes known from mature TCs do influence Sinlaku's cyclone structure during ET, although they do not represent a major effect. Orographic lifting and the postponed ET by orographic blocking of cold air advection appear to have a larger influence on the kinematic and thermodynamic structure.

\section{Summary and discussion}

Using high-resolution modeling of a very well-observed case of ET near orography, Typhoon Sinlaku (2008), this study investigates the impact of orography on the evolution of ET. Previous studies mainly mentioned enhanced precipitation by orographic lifting. Here, we considered a kinematic and thermodynamic perspective and focused on the influence of orography on structural changes of the vortex on the mesoscale and on the distribution of air masses on the mesoscale and synoptic scale. To do so, Sinlaku appears to be a very suitable case for this goal, due to its track close to Japan and unique data availability from the T-PARC field campaign.

Four mechanisms of structural changes of the cyclone, as known for landfalling TCs (idealized and real cases) with either no or weak steering flow, were tested here for a real case with a high translation speed. Orographically induced convergence caused an additional small precipitation area near Sinlaku's cyclone center, although the effect was only minor because an alreadyexisting asymmetric convergence field was dominant. Sinlaku's high translation speed prevents dry air originating over land to be advected toward the center, and the dry air therefore exerts no clear effect on the cyclone structure. A track deflection and the effect of differential friction on the cyclone structure were not observed either, because the strong environmental steering flow and the effect of orography were dominant. Nevertheless, Sinlaku's vortex structure was more symmetric and compact due to channeling, with locally enhanced updrafts by orographic lifting.

Regarding airmass distribution, it was found that cold air was blocked by the orography of Japan and could not be advected toward the cyclone. On the synoptic scale, midlatitude air from the north could not reach Sinlaku. The cyclone remained in a relatively warm environment and could not interact with cold midlatitude air until it moved away from the orographic barrier. On the mesoscale, evaporatively cooled air south of the mountains was blocked as well. Only when local orography was favorable for advection of this evaporatively cooled air could it reach Sinlaku for a short period of a few hours. Overall, the transformation stage of ET is delayed in the presence of orography. If no orography was present, the transformation occurs gradually and resembles a classic ET. The first interaction of the TC with colder air is the mesoscale evaporatively cooled air that is associated with vertical wind shear (step 2 of ET's transformation stage), as also described by Riemer et al. $(2010,2013)$ for mature TCs. This is followed by the synoptic-scale advection of midlatitude air from the north (step 3 of ET's transformation stage).

While our results demonstrate that the transformation stage of Sinlaku's ET has been delayed by the presence of orography, the question of whether orography influenced the tropical reintensification cannot be fully answered yet. Several factors that are independent of orography may influence reintensification. First, the sea surface temperature south of Shikoku was still $>26^{\circ} \mathrm{C}$, favorable for TC development (not shown). Second, Kuo et al. (2012) mentioned that two convective rainbands wrapped into the center, which can influence an intensification. Third, Foerster et al. (2014) argued that the reintensification was supported by the influence of vertical wind shear, enhancing upward motion in the downtilt-left quadrant of a storm. The rainband of Sinlaku was located mainly in the downtilt quadrant also. This behavior was, however, similar for both CNTRL and JFLAT and can therefore not be attributed to orography. Nevertheless, the intensification was slightly stronger and the cyclonic system was more compact in CNTRL, whereas colder air was present near the cyclone earlier in its development in JFLAT. This was also reflected in Sinlaku's wind field that kept its tropical characteristics for a longer period in the presence of orography. It is therefore hypothesized that Sinlaku was able to reintensify in the warm, moist, and potentially 
unstable environment south of Japan and could maintain its tropical and compact structure for a longer period due to the orographic blocking of colder air.

This study showed the importance of orography on the development of ET. Forecasters should be aware of the effects of orography on the already-changing cyclone structure. In addition to enhanced precipitation, as documented in literature, the intensity of the wind field can increase (e.g., by channeling in the densely populated coastal areas). Moreover, orography may lead to additional forecast errors because mountains are often not well represented in numerical models due to an inadequate resolution. Orography is naturally very inhomogeneous, and the orographic orientation of Japan is fairly different from that of, for example, New Zealand and the U.S. East Coast. Additionally, not all cyclones move parallel to the topography like Sinlaku did. Therefore, the influences that orography exerts on other ET cases may be different or present for a shorter period. This study gives important information on the impact of orography on ET, but in order to obtain a more general understanding of orography on the cyclone structure and the forecast errors associated with it, the orographic impact on ET should be tested further. Therefore, we propose the analysis of idealized cases with and without orography and varying types of environmental flow, complemented with an investigation of multiple real cases of ET near land, as fruitful topics for future work.

Acknowledgments. This study is part of HSL's Ph.D. thesis. The project was funded by the German Research Foundation (DFG) as part of the research unit PANDOWAE (FOR896). CMG's contribution was supported by the Swiss National Science Foundation (SNSF) Grant PZ00P2 148177/1 and finished while he holds a Helmholtz Young Investigator Group Grant (VH-NG-1243). MR acknowledges support from the DFG Collaborative Research Center "Waves to Weather" (TRR 165), project A4: "Evolution and predictability of storm structure during extratropical transition of tropical cyclones." Observational data were obtained in the framework of T-PARC. We thank the international consortium that supported the T-PARC field campaign and acknowledge the involvement of the U.S. National Science Foundation (NSF)-sponsored National Center for Atmospheric Research (NCAR) Earth Observing Laboratory (EOL) for data management and quality control. The authors are grateful to Martin Weissmann for kindly providing the ECMWF research analysis data and to Michael M. Bell and Annette M. Foerster for computing and providing additional gridded observational data with the SAMURAI software. The first author is also grateful to Leonhard Gantner and Christian Barthlott for technical support with the COSMO model; to Linda Schneider for her help with orography removal in INT2LM; and to Michael Sprenger, Daniel Luethi, and Gregor Pante for technical support concerning LAGRANTO. The Steinbuch Centre for Computing (SCC) at KIT is acknowledged for providing access to and support for their supercomputing facilities. The authors thank Joaquim G. Pinto for his helpful comments during the writing process. We thank two anonymous reviewers and the editor Ron McTaggart-Cowan for their thorough comments that helped to further improve the presentation of our results.

\section{REFERENCES}

Atallah, E. H., and L. F. Bosart, 2003: The extratropical transition and precipitation distribution of Hurricane Floyd (1999). Mon. Wea. Rev., 131, 1063-1081, https://doi.org/10.1175/15200493(2003)131<1063:TETAPD > 2.0.CO;2.

Barthlott, C., B. Adler, N. Kalthoff, J. Handwerker, M. Kohler, and A. Wieser, 2016: The role of Corsica in initiating nocturnal offshore convection. Quart. J. Roy. Meteor. Soc., 142, 222-237, https://doi.org/10.1002/qj.2415.

Bell, M. M., M. T. Montgomery, and K. A. Emanuel, 2012: Air-sea enthalpy and momentum exchange at major hurricane wind speeds observed during CBLAST. J. Atmos. Sci., 69, 31973222, https://doi.org/10.1175/JAS-D-11-0276.1.

Bosart, L. F., and D. B. Dean, 1991: The Agnes rainstorm of June 1972: Surface feature evolution culminating in inland storm redevelopment. Wea. Forecasting, 6, 515-537, https://doi.org/ 10.1175/1520-0434(1991)006<0515:TAROJS >2.0.CO;2.

Chan, J. C. L., and X. Liang, 2003: Convective asymmetries associated with tropical cyclone landfall. Part I: $f$-plane simulations. J. Atmos. Sci., 60, 1560-1576, https://doi.org/10.1175/ 1520-0469(2003)60<1560:CAAWTC $>2.0 . C O ; 2$.

Chang, S. W.-J., 1982: The orographic effects induced by an island mountain range on propagating tropical cyclones. Mon. Wea. Rev., 110, 1255-1270, https://doi.org/10.1175/1520-0493(1982) $110<1255$ :TOEIBA $>2.0$. CO;2.

Colle, B. A., 2003: Numerical simulations of the extratropical transition of Floyd (1999): Structural evolution and responsible mechanisms for the heavy rainfall over the Northeast United States. Mon. Wea. Rev., 131, 2905-2926, https://doi.org/10.1175/ 1520-0493(2003)131<2905:NSOTET>2.0.CO;2.

DiMego, G. J., and L. F. Bosart, 1982a: The transformation of Tropical Storm Agnes into an extratropical cyclone. Part I: The observed fields and vertical motion computations. Mon. Wea. Rev., 110, 385-411, https://doi.org/10.1175/1520-0493(1982) $110<0385$ :TTOTSA $>2.0$.CO;2.

$\longrightarrow$, and $-1982 \mathrm{~b}$ : The transformation of Tropical Storm Agnes into an extratropical cyclone. Part II: Moisture, vorticity and kinetic energy budgets. Mon. Wea. Rev., 110, 412-433, https:// doi.org/10.1175/1520-0493(1982)110<0412:TTOTSA > 2.0.CO;2.

Doms, G., and Coauthors, 2011: A description of the nonhydrostatic regional COSMO model. Part II: Physical parameterization. Consortium for Small-Scale Modelling Rep., 161 pp., http://www.cosmo-model.org/content/model/documentation/ core/cosmoPhysParamtr.pdf.

Ehmele, F., C. Barthlott, and U. Corsmeier, 2015: The influence of Sardinia on Corsican rainfall in the western Mediterranean Sea: A numerical sensitivity study. Atmos. Res., 153, 451-464, https://doi.org/10.1016/j.atmosres.2014.10.004. 
Evans, C., and Coauthors, 2017: The extratropical transition of tropical cyclones. Part I: Cyclone evolution and direct impacts. Mon. Wea. Rev., 145, 4317-4344, https://doi.org/10.1175/MWR-D-17-0027.1.

Foerster, A. M., M. M. Bell, P. A. Harr, and S. C. Jones, 2014: Observations of the eyewall structure of Typhoon Sinlaku (2008) during the transformation stage of extratropical transition. Mon. Wea. Rev., 142, 3372-3392, https://doi.org/10.1175/ MWR-D-13-00313.1.

Harr, P. A., R. L. Elsberry, and T. F. Hogan, 2000: Extratropical transition of tropical cyclones over the western North Pacific. Part II: The impact of midlatitude circulation characteristics. Mon. Wea. Rev., 128, 2634-2653, https://doi.org/10.1175/ 1520-0493(2000)128<2634:ETOTCO > 2.0.CO;2.

Hart, R. E., and J. L. Evans, 2001: A climatology of the extratropical transition of Atlantic tropical cyclones. J. Climate, 14, 546-564, https://doi.org/10.1175/1520-0442(2001)014<0546: ACOTET $>2.0 . \mathrm{CO} ; 2$.

Jian, G.-J., and C.-C. Wu, 2008: A numerical study of the track deflection of Supertyphoon Haitang (2005) prior to its landfall in Taiwan. Mon. Wea. Rev., 136, 598-615, https://doi.org/ 10.1175/2007MWR2134.1.

Jones, S. C., and Coauthors, 2003: The extratropical transition of tropical cyclones: Forecast challenges, current understanding, and future directions. Wea. Forecasting, 18, 1052-1092, https:// doi.org/10.1175/1520-0434(2003)018<1052:TETOTC>2.0.CO;2.

Klein, P. M., P. A. Harr, and R. L. Elsberry, 2000: Extratropical transition of western North Pacific tropical cyclones: An overview and conceptual model of the transformation stage. Wea. Forecasting, 15, 373-395, https://doi.org/10.1175/15200434(2000)015<0373:ETOWNP>2.0.CO;2.

Kossin, J. P., and C. S. Velden, 2004: A pronounced bias in tropical cyclone minimum sea level pressure estimation based on the Dvorak technique. Mon. Wea. Rev., 132, 165-173, https://doi.org/ 10.1175/1520-0493(2004)132<0165:APBITC > 2.0.CO;2.

Kuo, H.-C., C.-P. Chang, and C.-H. Liu, 2012: Convection and rapid filamentation in Typhoon Sinlaku during TCS-08/ T-PARC. Mon. Wea. Rev., 140, 2806-2817, https://doi.org/ 10.1175/MWR-D-11-00314.1.

Lackmann, G., 2011: Midlatitude Synoptic Meteorology: Dynamics, Analysis, and Forecasting. Amer. Meteor. Soc., 348 pp.

Lentink, H. S., 2017: Mechanisms determining structural changes during the extratropical transition of Typhoon Sinlaku (2008): A modelling study. Ph.D. thesis, Karlsruhe Institute of Technology, 203 pp., https://publikationen.bibliothek.kit.edu/ 1000074107.

Li, Y., K. K. W. Cheung, and J. C. L. Chan, 2014: Numerical study on the development of asymmetric convection and vertical wind shear during tropical cyclone landfall. Quart. J. Roy. Meteor. Soc., 140, 1866-1877, https://doi.org/10.1002/qj.2259.

,-- , and,- 2015 : Modelling the effects of land-sea contrast on tropical cyclone precipitation under environmental vertical wind shear. Quart. J. Roy. Meteor. Soc., 141, 396-412, https:// doi.org/10.1002/qj.2359.

Lin, Y.-L., S.-Y. Chen, C. M. Hill, and C.-Y. Huang, 2005: Control parameters for the influence of a mesoscale mountain range on cyclone track continuity and deflection. J. Atmos. Sci., 62, 1849-1866, https://doi.org/10.1175/JAS3439.1.

Quinting, J. F., M. M. Bell, P. A. Harr, and S. C. Jones, 2014: Structural characteristics of T-PARC Typhoon Sinlaku during its extratropical transition. Mon. Wea. Rev., 142, 1945-1961, https://doi.org/10.1175/MWR-D-13-00306.1.
Riemer, M., M. T. Montgomery, and M. E. Nicholls, 2010: A new paradigm for intensity modification of tropical cyclones: Thermodynamic impact of vertical wind shear on the inflow layer. Atmos. Chem. Phys., 10, 3163-3188, https://doi.org/10.5194/acp-10-3163-2010.

,-- , and -2013 : Further examination of the thermodynamic modification of the inflow layer of tropical cyclones by vertical wind shear. Atmos. Chem. Phys., 13, 327-346, https://doi.org/10.5194/acp-13-327-2013.

Ritchie, E. A., and R. L. Elsberry, 2001: Simulations of the transformation stage of the extratropical transition of tropical cyclones. Mon. Wea. Rev., 129, 1462-1480, https://doi.org/10.1175/ 1520-0493(2001)129<1462:SOTTSO > 2.0.CO;2.

Sanabia, E. R., 2010: The re-intensification of Typhoon Sinlaku (2008). Ph.D. thesis, Naval Postgraduate School, 233 pp., http://hdl.handle.net/10945/10534.

Schneider, L., C. Barthlott, A. I. Barrett, and C. Hoose, 2018: The precipitation response to variable terrain forcing over low mountain ranges in different weather regimes. Quart. J. Roy. Meteor. Soc., 144, 970-989, https://doi.org/10.1002/qj.3250.

Sinclair, M. R., 1993: A diagnostic study of the extratropical precipitation resulting from Tropical Cyclone Bola. Mon. Wea. Rev., 121, 2690-2707, https://doi.org/10.1175/1520-0493(1993) $121<2690$ :ADSOTE $>2.0$.CO;2.

Sprenger, M., and H. Wernli, 2015: The LAGRANTO Lagrangian analysis tool-Version 2.0. Geosci. Model Dev., 8, 2569-2586, https://doi.org/10.5194/gmd-8-2569-2015.

Srock, A. F., and L. F. Bosart, 2009: Heavy precipitation associated with southern Appalachian cold-air damming and Carolina coastal frontogenesis in advance of weak landfalling Tropical Storm Marco (1990). Mon. Wea. Rev., 137, 2448-2470, https:// doi.org/10.1175/2009MWR2819.1.

Steppeler, J., G. Doms, U. Schättler, H. W. Bitzer, A. Gassmann, U. Damrath, and G. Gregoric, 2003: Meso-gamma scale forecasts using the nonhydrostatic model LM. Meteor. Atmos. Phys., 82, 75-96, https://doi.org/10.1007/s00703-001-0592-9.

Szeto, K. C., and J. C. L. Chan, 2010: Structural changes of a tropical cyclone during landfall: $\beta$-plane simulations. Adv. Atmos. Sci., 27, 1143-1150, https://doi.org/10.1007/s00376-009-9136-x.

Tang, C. K., and J. C. L. Chan, 2014: Idealized simulations of the effect of Taiwan and Philippines topographies on tropical cyclone tracks. Quart. J. Roy. Meteor. Soc., 140, 1578-1589, https://doi.org/10.1002/qj.2240.

Tiedtke, M., 1989: A comprehensive mass flux scheme for cumulus parameterization in large-scale models. Mon. Wea. Rev., 117, 1779-1800, https://doi.org/10.1175/1520-0493(1989)117<1779: ACMFSF $>2.0 . \mathrm{CO} ; 2$.

Wernli, H., and H. C. Davies, 1997: A Lagrangian-based analysis of extratropical cyclones. I: The method and some applications. Quart. J. Roy. Meteor. Soc., 123, 467-489, https://doi.org/ 10.1002/qj.49712353811.

Wong, M. L. M., and J. C. L. Chan, 2006: Tropical cyclone motion in response to land surface friction. J. Atmos. Sci., 63, 13241337, https://doi.org/10.1175/JAS3683.1.

Wu, C.-C., T.-H. Li, and Y.-H. Huang, 2015: Influence of mesoscale topography on tropical cyclone tracks: Further examination of the channeling effect. J. Atmos. Sci., 72, 3032-3050, https:// doi.org/10.1175/JAS-D-14-0168.1.

Yeh, T.-C., and R. L. Elsberry, 1993: Interaction of typhoons with the Taiwan orography. Part I: Upstream track deflections. Mon. Wea. Rev., 121, 3193-3212, https://doi.org/10.1175/15200493(1993)121<3193:IOTWTT>2.0.CO;2. 